\title{
Vitamin D Deficiency: The Unrecognized Cause of Flank Pain
}

Dina O Abdulazima ${ }^{1}$, Mona M Salemb ${ }^{2}$, Mohammed Hassanc ${ }^{3}$, Ahmed Abdoc $^{3}$, Esam Rashadc ${ }^{3}$, Usama AA Sharaf EI Din ${ }^{*}$

${ }^{1}$ Department of Rheumatology and Rehabilitation, School of Medicine, Cairo University, Egypt

${ }^{2}$ International Kidney Center, Cairo University, Egypt

${ }^{3}$ Fellow of Nephrology, International Kidney Center, Cairo University, Egypt

${ }^{4}$ Professor of Nephrology, International Kidney Center, Cairo University, Egypt

"Corresponding author: Sharaf El Din UAA, Professor of Nephrology, International Kidney Center, Cairo University, 58th Abbas El Akkad St., Cairo, Egypt, Tel: +201111333800; Fax: +20222753890; E-mail: usamaaas@gmail.com

Received date: Aug 12, 2017; Accepted date: Aug 21, 2017; Published date: Aug 28, 2017

Copyright: (c) 2017 Abdulazima DO, et al. This is an open-access article distributed under the terms of the Creative Commons Attribution License, which permits unrestricted use, distribution, and reproduction in any medium, provided the original author and source are credited.

\begin{abstract}
Background: Loin pain is frequently not associated with any urinary abnormality. Musculoskeletal abnormalities are not uncommon as alternative cause of flank pain. Osteomalacia of the ribs was infrequently encountered as the cause of flank pain. Vitamin D deficiently has been reported as common problem worldwide with special predilection to Middle East area.
\end{abstract}

Objective: In this study, we looked for vitamin D deficiency in patients with flank pain associated with tenderness over the tips of the lowermost ribs.

Cases and methods: Out of 783 patients presenting with unilateral or bilateral flank pain to a single center over a period of 3 years, 316 did not have a definite urologic cause (group B). One hundred eighty seven of these patients had distinct tenderness over the costal margin (groupB1) that could not be explained by history and radiology. All patients of group $B$ were tested for serum level of $25(\mathrm{OH})$ vitamin $D$.

Results: Very low serum level of $25(\mathrm{OH})$ vitamin D was detected in all cases of group B1 and in only in only $26.4 \%$ of the remaining cases of group B (group B2). Relief of flank pain was noticed within 2 months in $55.1 \%$ of vitamin $\mathrm{D}$ deficient cases.

Conclusion: In patients presenting with flank pain, the existence of tenderness of the last ribs instead of the renal angle proper should alert to a possible cause in the rib cage. Estimation of serum vitamin $D$ level should be performed in these cases.

Keywords: Loin pain; Flank pain; Nephrolithiasis; Osteomalacia Vitamin D deficiency; $25(\mathrm{OH})$ vitamin D

\section{Introduction}

Flank pain is an important symptom of different urologic diseases. Beside urologic causes, gastrointestinal, musculoskeletal, pleural and neurologic diseases might be the source of this pain instead. The pain related to the last three ribs usually mimics renal pain. Because the definite cause of pain related to these ribs was not recognized in most cases, the term ' 12 th rib syndrome' was suggested. Unfortunately, this syndrome is frequently overlooked, especially after the routine use of spiral non-contrast computerized tomography (SCT) to investigate patients presenting with flank pain and neglect of thorough clinical examination. Clinical examination to elicit tenderness over the tip of the lowermost ribs is necessary to raise this possibility [1]. The 'hooking maneuver', first described in 1977, is a good alternative test [2]. The examining clinician can do this test by insinuating the hand underneath the costal margin and pulling anteriorly. This maneuver can elicit pain of variable severity. The 12th rib syndrome was first described in 1919 as one of the causes of flank pain [3]. Consequently, further newer reports have further characterized the condition [4-6]. These newer reports were mostly anecdotal or descriptive case series.
However, two investigators reported this syndrome in $1-5 \%$ of patients attending internal medicine or gastro-enterology clinics $[7,8]$. The underlying pathology of the 12th rib syndrome was not defined. Osteomalacia of the ribs as the cause of flank pain in a Vietnamese patient was disclosed by a recent case report [9]. The long-term use of tenofovir was behind osteomalacia in this case. Six years earlier, Sievenpiper et al. have described a fifty three year old Pakistani woman with history of mastectomy of the right breast for invasive ductal carcinoma 2 years earlier. This lady presented on follow-up with musculoskeletal pains at different sites including the right loin. She was initially managed with multiple courses of chemotherapy that failed to control her symptoms. Later on, she was accidentally discovered to have severe vitamin $\mathrm{D}$ deficiency $[10,11]$.

\section{Material and Methods}

This study spent three years starting by January 2014 to evaluate 783 consequetive patients that presented with distressing unilateral or bilateral flank pain to the international kidney center, Nasr City, Cairo, Egypt. After routine history taking, and clinical examination, these patients underwent routine laboratory, and imaging workup including abdomino-pelvic ultrasonography and spiral non-contrast computerized tomography (SCT) of the urinary tract. 567 cases proved 
Citation: Abdulazima DO, Salemb MM, Hassanc M, Abdoc A, Rashadc E, et al. (2017) Vitamin D Deficiency: The Unrecognized Cause of Flank

Page 2 of 3

to have a urology cause for their presenting pain (group A). These causes included stones, pelvi-ureteric junction and ureteric obstruction, urinary tract infection and renal cysts or neoplasms. Among the patients who had negative urine analysis and imaging studies (316 cases, group B), 187 cases have shown appreciable tenderness elicited on palpating the lowermost ribs at the costal margin on either side of the thoracic cage with maximum tenderness over the tips of the involved ribs (group B1). The routine laboratory and imaging studies of these patients excluded the urinary tract as the cause of flank pain in these cases. The possibility of osteomalacia was raised. Accordingly, serum level of calcium, phosphorus, alkaline phosphatase, $25(\mathrm{OH})$ vitamin $\mathrm{D}$ and Parathyroid Hormone (PTH) were tested for all patients of group B1 and group B2. Microsoft computer statistics package was used for data analysis. Data were summarized as mean and standard deviation. Comparison between groups was evaluated using Student's t-test.

\section{Results}

Results are summarized in Tables 1 and 2. The serum level of 25 $(\mathrm{OH})$ vitamin $\mathrm{D}$ disclosed moderate to severe vitamin $\mathrm{D}$ deficiency in subjects of group B1.

\begin{tabular}{|c|c|c|c|c|c|}
\hline \multirow{2}{*}{ Parameter } & \multicolumn{2}{|l|}{ Group B1 } & \multicolumn{2}{|l|}{ Group B2 } & \multirow{3}{*}{$\begin{array}{l}\text { P value } \\
<0.01\end{array}$} \\
\hline & Range & Mean \pm S.D. & Range & Mean \pm S.D. & \\
\hline Age (years) & $19-65$ & $38 \pm 8.75$ & $26-43$ & $37 \pm 4.87$ & \\
\hline Gender (M/F) & \multicolumn{2}{|l|}{$11 / 176$} & \multicolumn{3}{|l|}{$14 / 115$} \\
\hline BMI $\left(\mathrm{kg} / \mathrm{m}^{2}\right)$ & $19.5-36$ & $29.5 \pm 2.71$ & $17.5-31$ & $24 \pm 2.99$ & $<0.001$ \\
\hline BUN (mg/dL) & 8-35 & $11 \pm 3.91$ & $12-25$ & $10.9 \pm 3.34$ & N.S. \\
\hline Serum Creatinine (mg/dL) & $0.6-2.3$ & $0.9 \pm 0.57$ & $0.6-2.0$ & $0.93 \pm 0.49$ & N.S. \\
\hline Serum Calcium (mg/dL) & $7.9-9.2$ & $8.5 \pm 0.28$ & $8.1-9.1$ & $8.4 \pm 0.3$ & N.S. \\
\hline Serum Phosphorus (mg/dL) & $3.0-4.8$ & $4.1 \pm 0.64$ & 3.4-5.5 & $4 \pm 0.67$ & N.S. \\
\hline Serum Alkaline phosphatase (U/L) & $55-186$ & $128 \pm 38$ & $44-140$ & $119 \pm 27$ & $<0.01$ \\
\hline Serum PTH $(\mathrm{pg} / \mathrm{mL})$ & 44.3-198.5 & $87.8 \pm 14.04$ & $44-51.4$ & $47.9 \pm 2.52$ & $<0.001$ \\
\hline Serum $25(\mathrm{OH})$ Vitamin D D (ng/mL) & $4.8-21$ & $12.8 \pm 5.8$ & $21.8-49.8$ & $37 \pm 8.43$ & $<0.001$ \\
\hline Serum Uric acid (mg/dL) & $3.7-7.9$ & $4.9 \pm 1.13$ & $4-5.9$ & $4.9 \pm 0.48$ & N.S. \\
\hline
\end{tabular}

Table 1: Demographic data and laboratory investigations.

\begin{tabular}{|c|c|c|c|c|c|}
\hline \multirow{2}{*}{ Parameter } & \multicolumn{2}{|l|}{ Group B1 } & \multicolumn{2}{|l|}{ Group B2 } & \multirow{3}{*}{$\begin{array}{l}\text { P value } \\
\text { N.S. }\end{array}$} \\
\hline & Range & Mean \pm S.D. & Range & Mean \pm S.D. & \\
\hline Age (years) & $19-59$ & $34 \pm 6.5$ & $27-41$ & $34.4 \pm 4.06$ & \\
\hline Gender (M/F) & \multicolumn{2}{|l|}{$9 / 147$} & \multicolumn{3}{|l|}{$13 / 93$} \\
\hline BMI $\left(\mathrm{kg} / \mathrm{m}^{2}\right)$ & $21-36$ & $29.1 \pm 2.2$ & $22.5-31$ & $25.6 \pm 2.09$ & $<0.001$ \\
\hline $\mathrm{BUN}(\mathrm{mg} / \mathrm{dL})$ & $8-17$ & $10 \pm 2.11$ & $12-18$ & $10.2 \pm 1.85$ & N.S. \\
\hline Serum Creatinine (mg/dL) & $0.6-1.1$ & $0.8 \pm 0.1$ & $0.6-1.0$ & $0.8 \pm 0.09$ & N.S. \\
\hline Serum Calcium (mg/dL) & $8.1-9.2$ & $8.6 \pm 0.25$ & $8.1-9.0$ & $8.5 \pm 0.27$ & N.S. \\
\hline Serum Phosphorus (mg/dL) & $3.0-4.2$ & $3.5 \pm 0.55$ & $3.4-4.3$ & $3.6 \pm 0.47$ & N.S. \\
\hline Serum Alkaline phosphatase (U/L) & $55-181$ & $127 \pm 37$ & $44-118$ & $95 \pm 19$ & $<0.001$ \\
\hline Serum PTH (pg/mL) & $49-198.5$ & $91.5 \pm 13.4$ & $44-48.6$ & $45.6 \pm 1.34$ & $<0.001$ \\
\hline Serum $25(\mathrm{OH})$ Vitamin D D (ng/mL) & $8-21$ & $14.4 \pm 5$ & $22.5-49.8$ & $37.3 \pm 7.6$ & $<0.001$ \\
\hline Serum Uric acid (mg/dL) & $3.7-6.4$ & $4.2 \pm 0.78$ & $4-5.1$ & $4.2 \pm 0.48$ & N.S. \\
\hline
\end{tabular}

Table 2: Demographic data and laboratory investigations after exclusion of CKD patients. 
Page 3 of 3

In addition, serum alkaline phosphatase and serum PTH were significantly higher in this group. In order to avoid the confounding effect of impaired kidney function on the studied parameters, further analysis was performed after exclusion of chronic kidney disease patients.

Thirty-one and twenty three cases were excluded in group B1 and group B2 respectively. The significant difference in serum levels of 25 hydroxy vitamin D, PTH and alkaline phosphatase between the 2 two groups was still observed (Table 2). When vitamin D deficient patient were prescribed vitamin D replacement, 55.1\% (103 patients) of group B1 reported dramatic relief of flank pain within two months after onset of replacement.

\section{Discussion and Conclusion}

The first report of osteomalacia as the cause of flank pain was in 2008. In this report, Sievenpiper et al. described a 53 years old Pakistani woman that was erroneously treated by chemotherapy when presented with pain in multiple sites including her right loin after radical mastectomy for breast cancer. This lady later proved to have severe vitamin $\mathrm{D}$ deficiency after she developed manifestations of hypocalcemia [10]. Six years later, Hamnvik et al. [9] described a Vietnamese patient with flank pain. The underlying mechanism of osteomalacia in this case was a consequence of the long-term use of tenofovir to treat chronic hepatitis B. However, vitamin D deficiency as a cause of localized unilateral or bilateral loin pain is not reported when the literature is searched. To our knowledge, this study is the first to disclose vitamin D deficiency as one of the causes of flank pain. $85 \%$ of patients in the present study are Egyptians. However, other nationalities of the adjacent Arab countries (Libya, Syria, Saudi Arabia, Yemen, Sudan, and Somali) were presented in the current study and constitute $15 \%$ of the cases. The prevalence of vitamin D deficiency in these countries is high in spite of the sunny weather most of the days. Lack of sun exposure is mostly related to social and religious habits. The poor nutrition in some of these countries is an additional factor.

In spite of the significant deficiency of vitamin $\mathrm{D}$ in these cases, the level of serum calcium and phosphorus failed to help in diagnosis. The significant increase of serum alkaline phosphatase and PTH in some of these cases might help in diagnosis in some cases. However, such approach is not sensitive or specific. The definitive diagnosis should be established by estimating serum $25(\mathrm{OH})$ vitamin D level. This statement should be amended to chronic kidney disease patients. The presence of bone pains in these cases before starting dialysis is unlikely attributed to bone mineral disorders encountered in these patients. The presence of tenderness over the rib tips instead of the renal angle must, therefore, raise the possibility of disease in the rib cage. After the exclusion of traumatic, inflammatory and neoplastic possibilities [12-15], estimation of serum 25-hydroxyl vitamin D level is advisable.

\section{Recommendation}

In patients with flank pain and positive signs of the 12th rib syndrome, investigations for vitamin $\mathrm{D}$ deficiency became necessary according to the present study.

\section{Ethical Committee Approval}

This work was approved by the local ethical committee of the International Kidney Center, Nasr City, Cairo, Egypt

\section{Acknowledgments}

Professor Usama and Professor Mona suggested the hypothesis and objectives of this study, Dr. Dina collected the necessary literature, all authors shared in collection of the study subjects, Prof. Usama wrote the manuscript, Dr Dina made the final revision.

\section{Conflict of Interest}

The authors have declared that no conflict of interest exists.

\section{Human and Animal Rights}

All procedures performed in this study involving human participants were in accordance with the ethical standards of the institutional and/or national research committee and with the 1964 Helsinki declaration and its later amendments or comparable ethical standards.

\section{Informed Consent}

"Informed consent was obtained from all individual participants included in the study."

\section{References}

1. Keoghane SR, Douglas J, Pounder D (2009) Twelfth rib syndrome: a forgotten cause of flank pain. BJU Int 103: 569-570.

2. Heinz GJ, Zavala DC (1977) Slipping rib syndrome. Diagnosis using the hooking maneuver. JAMA 237: 794-795.

3. Cyriax EF (1919) On various conditions that may simulate the referred pains of visceral disease, and a consideration of these from the point of view of cause and effect. Practitioner 102: 314-319.

4. Davies-Colley R (1922) Slipping rib. BMJ 1: 432.

5. Holmes JF (1941) Slipping rib cartilage. With report of cases. Am J Surg 54: 326-328.

6. Stevenson FH (1951) Nerve slipping at the intercostals margin. Lancet 258: 969-970.

7. Wright JT (1980) Slipping rib syndrome. Lancet 20: 632-634.

8. Scott EM, Scott BB (1993) Painful rib syndrome-A review of 76 cases. Gut 34: 1006-1008.

9. Hamnvik OP, Vaidya A, Becker C (2014) Interactive medical case: wasting away. N Engl J Med 370: e12.

10. Sievenpiper JL, McIntyre EA, Verrill M, Quinton R, Pearce SH (2008) Unrecognised severe vitamin D deficiency. BMJ 336: 1371-1374.

11. Demirbilek H, Aydogdu D, Ozon A (2012) Vitamin D-deficient rickets mimicking ankylosing spondylitis in an adolescent girl. Turk J Pediatr 54: 177-179.

12. Bodey B (2005) Spontaneous regression of neoplasms: new possibilities for immunotherapy. Expert Opin Biol Ther 2: 459-476.

13. Barcellos-Hoff MH (2015) BUB1-bling over with Possibilities. Neoplasia 17: 153-154.

14. Bodey B (2002) Spontaneous regression of neoplasms: New possibilities for immunotherapy. Expert Opin Biol Ther 2: 459-476.

15. Rosenwald IB (2004) The role of translation in neoplastic transformation from a pathologist's point of view. Oncogene 23: 3230-3247. 